\title{
C2: A Modern Approach to Disaster Management
}

\author{
Kumar Surjeet Chaudhury \\ Computer science and \\ Engineering, Jadavpur \\ University, Kolkata, West \\ Bengal State 700032, India
}

\author{
Arpita Nibedita \\ Computer science and \\ Engineering, WBUT, \\ Kolkata, West Bengal \\ State 700106, India
}

\author{
Soumyashree Sahoo \\ Computer Science and \\ Engineering, BPUT, \\ Orissa, India
}

\begin{abstract}
A disaster is a serious disruption of the functioning of society, causing widespread human, material or environmental losses. The disaster can be avoided by "disaster management", which means a continuous and integrated process of planning, organizing, coordinating and implementing measures which are necessary or expedient for prevention of danger or threat of any disaster. Henceforth considering the command and control aspect of disaster management, a command and control system called $\mathrm{C} 2$ model has been designed in this paper for mitigation or reduction of risk of any disaster or its severity or consequences. The theory of command and control is changing with the emergence of new adversaries challenging the system and new technologies supporting it. Challenges instigate changes in strategy to accommodate them while new technologies enable new capabilities. These two forces drive the development of $\mathrm{C} 2$ theory. Command and control encompasses all planning and response functions and operations, giving them meaning and harmonizing them into a meaningful whole. Command and control is the means by which a commander recognizes what needs to be done and sees to it that appropriate actions are taken. Sometimes this recognition takes the form of a conscious command decision, as in deciding on a concept of operations. Sometimes it takes the form of a preconditioned reaction, as in immediate-action drills, practiced in advance so that we can execute them reflexively in a moment of crisis.
\end{abstract}

\section{Keywords}

C2 (command and control), disaster management, Wi-max Technology, PDA

\section{INTRODUCTION}

Command and Control system may be a solution to the disaster management. Command and control involves the complex collection of functions and systems an executive draws on to arrive at decisions and to see they are carried out, Thus, the acronym $\mathrm{C} 2$ may be used to refer to anything from information to sophisticated communications and computer equipment, to the executive's own mind-the last involving education, training, experience, native intelligence, and other aspects of cognition. In May 1960,Defense secretary Thomas $\mathrm{S}$. gates directed for the creation of Defense communication system represented in substantial measure an effort to achieve greater economies by integrating the services' separate longhaul communications systems[1]. The need having been established, in May 1961, US president, Mr. Kennedy called for the creation of a command and control system that, although located within the Department of Defense, would be responsive to the needs of central decision makers and remain under ultimate civilian control at all times. In the late 1970s, in response to a lengthy series of failures and snafus in various components of the Defense Department's World Wide
Military Command and Control System (WWMCCS), a remarkable and rather unlikely team of consultants was assembled at the Pentagon, USA. Their job was to try to figure out how to make the vast, multibillion dollar metasystem of sensors, command centers, and communications links work better. The group included 30 anthropologists and sociologists, mathematicians, control theorists and systems theorists, and representatives from a variety of other scholarly disciplines. Thereafter many automated system such as strategic automated command control system and nuclear planning and execution system follows this command and control strategy to develop their systems [6]. The theory of command and control is changing with the emergence of new adversaries challenging the system and new technologies supporting it. Challenges instigate changes in strategy to accommodate them while new technologies enable new capabilities. These two forces drive the development of $\mathrm{C} 2$ theory [2]. The first response to uncertainty is to try to minimize it by creating a powerful, highly efficient command and control apparatus (Command Structure) able to process huge amounts of information and intended to reduce nearly all unknowns. The result is Strict Command and Control. Such a system stems from the belief that if we can impose order and certainty on the disorderly and uncertain disaster affected area, then successful results are predictable. As the disasters are so much unstructured in scope, when it strikes different communities like human, animal, plant will suffer at front. According to the $\mathrm{C} 2$ model, whenever there is a disaster, the command or actions to be taken is released by the government authority and pass to its lower levels and different other organizations for implementation. The command is issued after collecting relevant information from them and its lower levels. The national disaster system can employ detailed command and control. Unfortunately, detailed C2 is poorly equipped to deal with uncertainty due to fog in the environment, complexity due to friction and variability that inevitably results from complexity, and the interaction of numerous, independent agencies or organizations.

\section{PROPOSED C2 SYSTEM FOR DISASTER MANAGEMENT}

Therefore for better management a command and control model for disaster management is proposed. This approach accepts the turbulence and uncertainty of disaster. Rather than increase the level of certainty that $\mathrm{C} 2$ seeks, this approach of command and control reduces the degree of uncertainty that we need [3]. This C2 for disaster management decentralizes decision-making authority and grants subordinates significant freedom of action. It is much more informal and flexible than detailed C2.It improves the ability to deal with fluid and disorderly situations. This approach of $\mathrm{C} 2$ for disaster management allows for both horizontal and broadcast information. Horizontal information saves time and increases situational awareness by moving information directly among 
agents in the field. Broadcast information from the commanders presents information to the field agents that they can process and act on autonomously. The proposed $\mathrm{C} 2$ system for disaster management can precisely be elaborated diagrammatically.

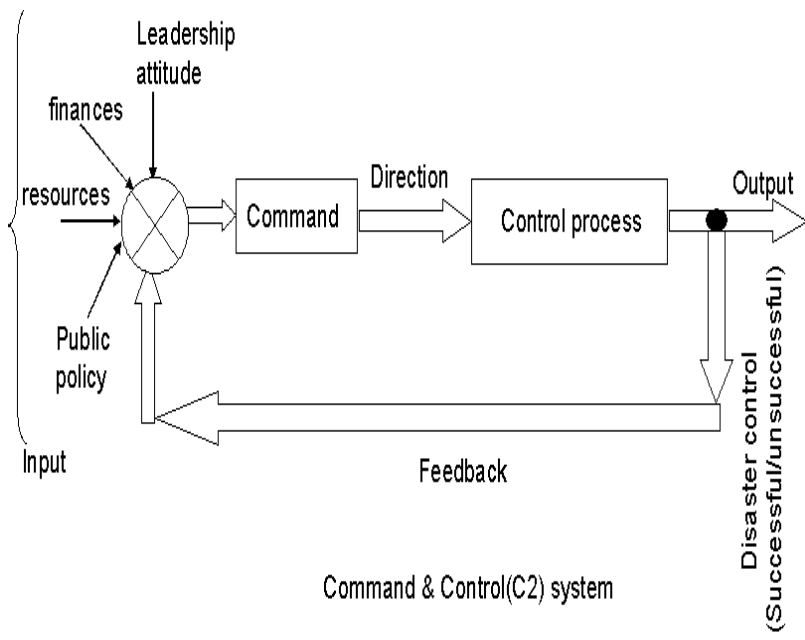

Fig 1:C2 System

This C2 model for disaster management decentralizes decision-making authority and grants subordinates significant freedom of action. It is much more informal and flexible than detailed C2. Variability requires adaptability. Field agents must respond quickly to changes in the environment. Applications will be bandwidth-aware and change their mode of transmission accordingly to accommodate a volatile network. The goal is to enable mutual understanding with limited exchanges of data.

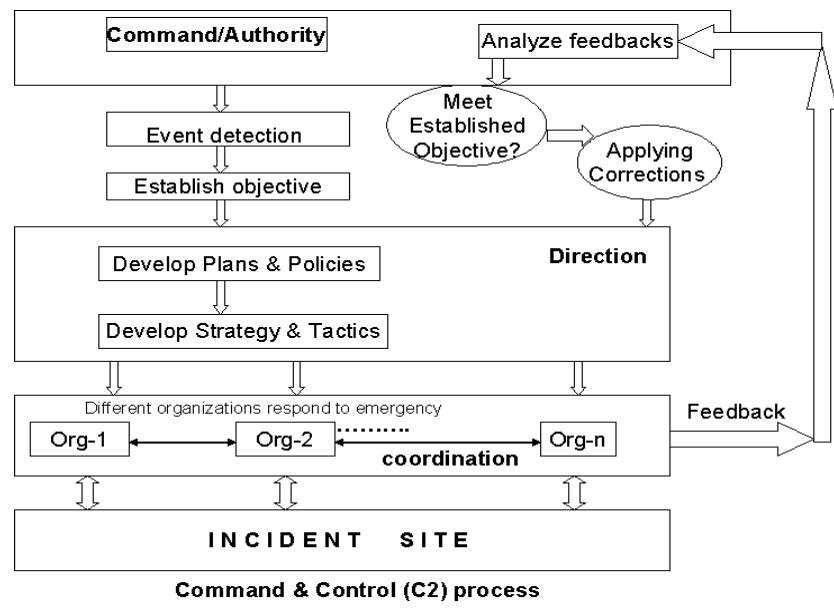

Fig 2: C2 Processes

\subsection{C2 Components: A Proposed Architecture in Indian Perspective}

This proposed system has at least three components; an organizational structure, management process and facilities from which to operate.

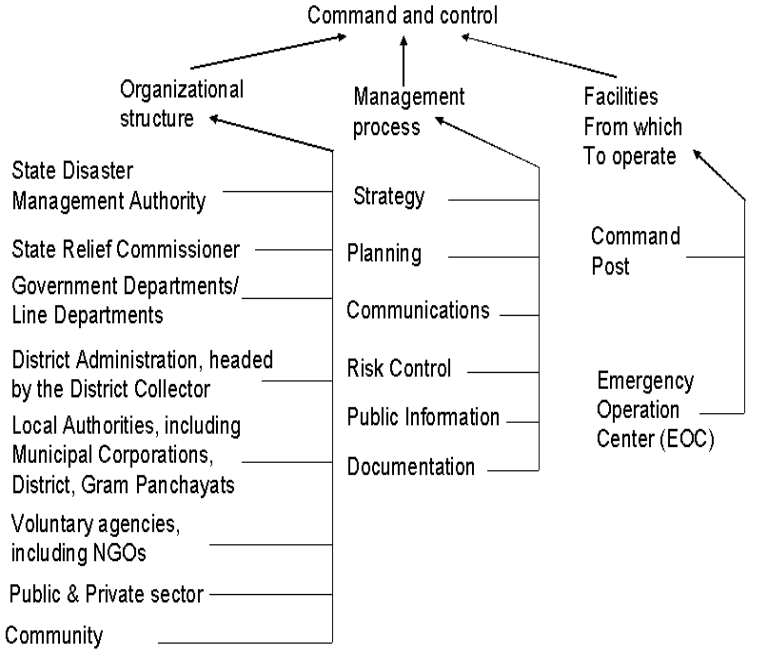

Fig 3: Components of $\mathrm{C} 2$ in Indian perspective

In the organizational structure, line departments includes various departments which will act as a nodal department during the disaster like police, civil defense, health, food and civil supply, fisheries, power, PWD, PHE, irrigation, agriculture etc. Administrative officers are the part of bureaucrat and elected persons like chairman of a municipality, sabhapati of panchayat samiti etc belongs to elected members. The strategy, planning, risk control, documentation etc are formulated by several committees and sub committees formed under National Disaster Management Authority (NDMA)[4] in which government employees are member of those committees.

\subsection{Role of communication in C2 system}

When any disaster approaches the existing communication system may be severely hampered. Hence it becomes essential for proper maintenance of the communication system [5]. The proper flow of information from the incident site to authority and simultaneously command or response direction from authority to incident site must be well communicated. However for this we need a communication system, which may be damaged due to disaster. There are two alternative methods possible for that purpose. First one is one need to restore the existing communication network which may take some hour or even some days or even months also Alternate method is after disaster breaks the existing network, if we are able to deploy a network rapidly (may be of Wi-Fi or wi-max) up to position where we have available network for communication, one can send information from the core incidental site to the authority. The information then flow from there to some higher authority and finally reaches an emergency operation center by any means. In general, the authority needs more and more details information from various incident sites with different sources within less time, the less difficulties he/she will face while taking the decision. Also the command and direction of command need proper communication system to finally reach to the responders. Taking in view of the above, a proper communication system is a crucial component in disaster management. 


\subsection{Proposed N/W architecture}

If a prior established communication system breaks by disaster then for continuation of response and relief operation, Which may includes various technologies like Wi-Fi or Wimax and extends this rapidly deployable communication network's range to the existing network reach-ability area. Keeping all the services and the constraint in the mind the architecture of the proposed system has been developed as the following. In this proposed network architecture is divided into five layers namely Frontier, Access, Backbone, Backhaul and Backend layer. The proposed-system should reach all the possible locations under disaster situations for data collection. Some personal digital assistant (PDA), for instance, mobile handheld devices can collect and transmit data. Network of such devices are named as Frontier Network. For the $1^{\text {st }}$ case, we need a device that connects PDA (s) together to form a Wireless network; this device is called a Wireless Access Point (WAP). A mesh network of such devices is required for the full coverage of the area under disaster siege, since, coverage of a single WAP may not be adequate, and it should be called Access Network. For the $2^{\text {nd }}$ case, a long range communication is required and the Access Network should be a connected to a Customer Premises Equipment (CPE) of the Long Range Communication Device. CPE will in turn communicate to a Base Transreceiver Station (BTS) or to a series of BTS (s) for further traveling of the data; this arrangement is named as Backhaul Network. Backhaul network will later merge to an existing Backbone Network wireless (GSM/CDMA) or wired network. After the travel via existing Backbone network, data will be deposited to Central Data Repository, which will be connected to different departmental Network via Internet for further distribution and processing of the said data, which we termed as Backend Network.

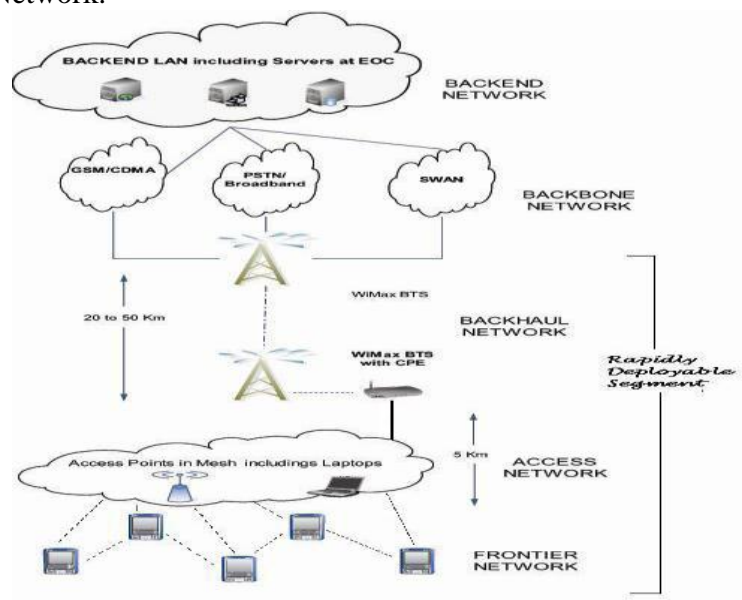

Fig 4: Proposed Architecture for Rapidly Deployable Network a rapidly deployable network system is needed. That means one need to establish any sort of communication method.

\section{CONCLUSION}

No one can predict at what exact time and how a disaster will strike. Therefore at every time we should awake of disaster. In democratic country like India, only the government is the solo organization who will act and take necessary actions to disaster. The government can allow different NGOs, private parties, different community based organizations to act or participate during an emergency. Thus any model for disaster management must follow the government rules and regulations. The national disaster system may employ detailed command and control. Unfortunately, detailed $\mathrm{C} 2$ is poorly equipped to deal with uncertainty, complexity and variability. Therefore for better management, a command and control disaster management can be described as spontaneous. Subordinates are guided not by detailed instructions and control measures but by their knowledge of the requirements of the overall mission. This $\mathrm{C} 2$ for disaster management decentralizes decision-making authority and grants subordinates significant freedom of action.

\section{REFERENCES}

[1] Pearson, David E. (David Eric), 1953- The world wide military command and control system: evolution and effectiveness.

[2]The future of command and control for disaster response. Joseph Rosen (Darthmouth-hitchcock medical center), Eliot Grig and Susan McGrath (Thayer School of Engineering, Dartmouth College), Jaron Lanier (Advance network and service Inc).

[3] Command and Control of Disaster Operations by Walter G. Green III, Ph. D., CEM ; Universal Publishers/ uPUBLISH.com, USA 2001.

[4] NDMA Act 2005 edition, Government of India, Department relief, New Delhi.

[5] Communication support system for emergency management Me Nakatani, Shinobu Yamasaki, Kosuke Takahashi, Yoshinon Hijikata.

[6]Command and control for war and peace, Thomas P.Coakley,with an introduction by Robert T.Herres National De fence University Press'Washington,DC. 